\title{
El Diseñador como Hacker
}

por Diego Gómez

\author{
"We can learn from the hackers, those machines of \\ possibility, to help carve out our possible futures." 1
}

-Alexander Galloway.

\section{Introducción}

El hacker es un activista radical quien a partir de la de-construcción; de la intervención activista unilateral; busca construir un nuevo entendimiento respecto de la capa zecno-política de la sociedad contemporánea. El diseñador de hoy tiene poco y nada de eso. En una mayoría abrumadora, el diseñador actual ha preferido concentrar su hacer en lo meramente operacional, reemplazando lo reflexivo por el interés en un ambiente de espectáculo.

Este artículo aborda precisamente, las relaciones posibles entre cultura hacker y el hacer de los diseñadores, áreas que a primera vista podrían parecer muy distantes. El objetivo central es contribuir al desarrollo de una discusión que se enfoque en analizar las ventajas de construir una nueva forma de practicar el diseño, nutrida con aspectos presentes en el hacer de los hackers. Para tales efectos iniciaré este texto enfocándome en el por qué es importante hoy observar aspectos del mundo hacker, para luego hacer un parangón con algunas de las prácticas artísticas que dieron vida a lo que actualmente denominamos diseño. Desde alli, me concentraré en presentar una validación de un perfil potencial para el diseñador-hacker, su relevancia en el contexto actual y los escenarios futuros, desde una perspectiva global y regional. Finalmente, concluiré este artículo señalando la importancia que esta perspectiva debería tener en la enseñanza y desarrollo del diseño dentro de centros universitarios complejos. 


\section{Por qqué Hacker}

He iniciado la introducción a este artículo con un áclaración que presenta el quehacer del hacker desde una perspectiva de aửmiración, constituyéndosé en una cuasia-apología. Más allá de mi intención de generar wna provocación argumental, estás primeras líneas transparentan las cualidades - a mi parecer poderosas - que observo en este interventor cultural denominado hacker. Sin enbargo, es cierto que este término debe ser abordado cambién con sus carargas negativas. Desde alli, el enrendimiento general asocia al hacher con un indiviauo joven -a veces adolescente -.- con amplios habilidades en el mannejo de compuradores y que tealiza ataques clectrónicos que podriar inplicar el robo de dinero a instituciones y/o personas o, dańos a la infraestructura digital de éstos. El componente subversivo en la cultura backer es una realidad que a pesar de sus aspectos conderables. debe ser también analizado en su capacidad de articular procesos de reflexión en la capara tecno-política de la sociedad. Con esto quiero decir que más allá de observar el fenómeno hacker meramente desde los jaicios éticos, que sin duda muchas veces son necesautios; es fundamental además axanzar hacia una profundización del potencial sociopolítico, que a través de la apropiación y reivindicación tecnobogica, conlleva este fenómeno.

Ahora bien, desde los aspectos del lenguaje, el termino backer presenta consideraciones interesantes para esce análisis. En inglés la definición del verbo ta hack en su primera actpción, implica cortar de manera dura y con golpes fuetes algo. Es decir, un hachazo. En una segunda acepción, el significado está dado por usar un computador para observar $\propto$ cambiar sin autorización la información al macenada en otro computador. Sin duda csta útrima definición es La más familiar para nosotros ya que se vincula al imaginario cultural donde situamos comúnmente al hacker. Sin embargo, existe también una varante lingüistica más informal para el verbo to hack, y que es vital de revisar aqui. Este uso es común dentro del fenómeno Da li Yotoself (ory') -hazlo tú mismo-y hace referencia al intervenir y modificar de tmanera no formai ni estandarizada, una piezá o producto electrónico. Así por ejemplo, "yotz saed ta batk it" podtia replicar en inglés alguien, si un terceto estuxiese pensando en yoz alta cómo añadir cualidades interactivas a una lámpara de velador convencional - cn castellano, sería algo asi como "necesitas hackeat la lámpara". Así, este tercer uso 
se mueve encre las don definiciones formales del término presentadas más arriba. Implica por un lado, obtener acceso no autorizado a un sistema, desarrollando aquello en un ambiente de infomalidad y arojo, a traves de una intervención intensa y fuerte de la techue. La concepción que du teste uso á término su vinculable a la filosofia que cxpresa Massimo Banzi para la plataforma de interacción física o

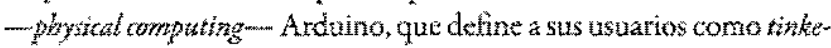
rem, es decir, aquellas personas que practican el verbo to tinker, o sea, reparar o mejorat algo sin contar con las habildades o conocimientos propios para tal acto'. De este modo, whacer del tizkerer se funde ton thacer alel hakktr, todo tsto, en el uso casual de lenguaje Asi mismo, al hacer una recapitulacion terminológica, se puede decir que la esencia de lo que he sertalado en las ứlmimas linteas, se encuentra en et entendimiento del concepro hacker en su vinculación y semejanza con el rémino tirkeres. Así $y$ en base a la información anterior, el perfil del baker que me interesa rescatar hasta aqui, es el del interventor que busca conocer y dominar la tecnologia con arrojo, para descubrir en tlla aquello que está oculco.

Ortos formas de entender el término bakker son ciertamente posibles. El periodista Misha Glenny, cryo trabaño se ha centrado en la irvestigación de las restes globales tejidas por a crinen organizado; especialmente dede Europa oriental; realizó en el TeD Gobal de Escocia en Julio de $20 x$ una presentación llamada "Hire the Hackers" (Contraten a los hackers), donde argumenta en favor de utilizar los takentos y capacidades de backens gue hayan participado de actos delictivos como método pata contrarrestar el alcance del crimen organizado, potenciar los esfuerzos en ober-5eguridad y a la vez, ayudart a la reinserción social de estos individuos.

Sin embargo, este artículo rributa de manera entusiasta a las ideas planteadas por Alexander Galloway, quien en su libro " Thtocol, nos muestra una visión del backer enfocada en el talento para la posibil: dad'. Para Galloway los batkers constituyen verdaderas máquinas de explonación de futuros posibles. En la muy interesante sccción titu. lada passibility de aquel libro, Calloway serala la estrecha relación encre la validación de lo utópico y la búsqueda conscante de lo posible. Desde alli, nos muestra al batke eminentemente como un actor político, como un acrivisa que persisze en abordar el control de la tecnologia para descfiarla, para íberar el conocimiento y el desarrollo de éste. Sin duda, y asi lo plantea Galloway, este axtivismo se desarrolta desde una moralidad particular y de carácter propio que parece rener como único objetivo el alcance de lo posible y donde el código - - odz- se presenta no sólo como vehículo del acto sino 
también como filosofia hecha forma y estructura, es decir, como lenguaje. Es precisamente este aspecto de intención y actitud activista, esta visión crítica desde la técrica la cual quieto rescatar acá como aspecto fundamental de este artículo.

Así, y en consideración de lo señalado en las definiciones del lenguaje y su uso, como también en las perspectivas de los escritores y teóricos que de manera explorativa he presentado, la definición de hacker en la que me interesa hacer foco para los fines argumentativos de este artículo, es la de aquel que busca conocer y dominar la tecnología con fuerza interventora y activista, para descubrir en ella aquello que está oculto, revelando su influencia política en la sociedad contemporánea.

\section{El mantenedor y el diseñador}

Una de las circunstancias que me ha empujado a escribir este artículo es la percepción de que como diseñadores hemos perdido el rumbo. Pareciera que en un gran porcentaje, el diseñador actual prefiere, e incluso desea, concentrar su carrera en el espectáculo y fuegos de artificio que propicia y alienta la sociedad de consumo occidental. Esto sin duda es una generalización ya que hay, ha habido y habrán importantes excepciones, pero las generalizaciones muchas veces son útiles para visualizar tendencias.

La ausencia de crítica y reflexión en el trabajo de los diseñadores se ha transformado en una constante. La mayoría de los hombres y mujeres que practican la disciplina buscan desarrollar sus carreras vinculándose de manera directa o indirecta - como provecdores o empleados - al manejo de las imágenes y productos que giran en torno a la producción de compañías de escala considerable. Incluso diseñadores jóvenes cuya historia personal ha tenido lazos con manifestaciones culturales urbanas tales como hip hop, graffitio skateboarding - y que generalmente catalogamos como expresiones críticas de la sociedad contemporánea - parecen mostrarse cómodos y motivados elaborando proyectos que ensalzan visual y formalmente los sistemas productivos dominantes. Al parecer ven en ello, el potencial necesario para obtener los grados de glamour y fama que los validen entre sus pares. Todo esto implica un abandono del rol intervencionista real en la cultura y significa optar por ejercer como operario de estilos y productor de identidades definidas de antemano por las estructuras organizacionales que manejan el mercado y la sociedad de consumo en buena parte del mundo. Esto es cicramente un problema y conlleva negar al diseñador para propiciar el rol del mantenedor. $Y$ es que por esencia el diseñar
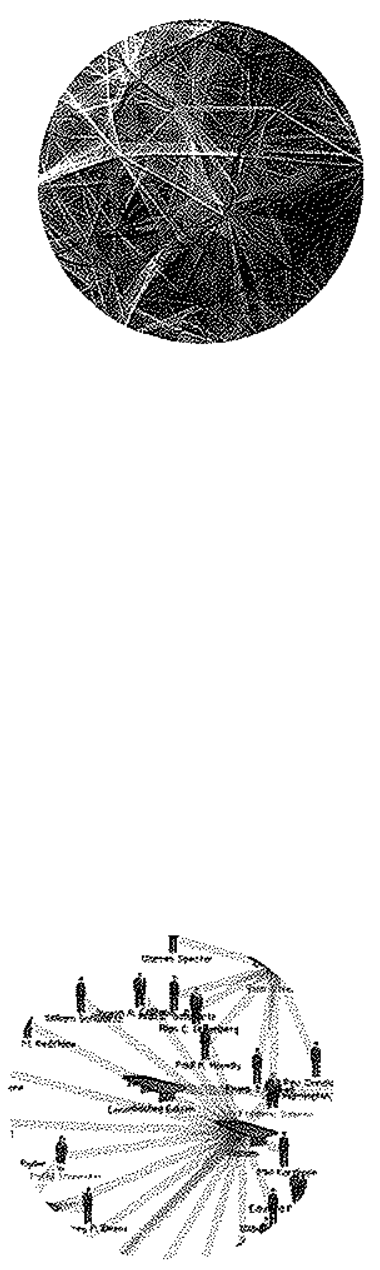

Ensayo 


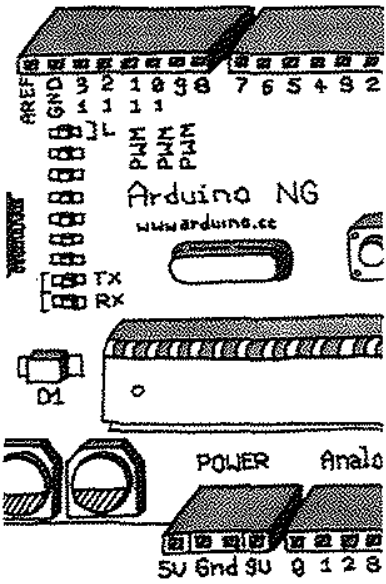

implica replantearse constantemente el presente para pensar futuros posibles y ensayar su construcción, siempre con perspectiva de interventor cultural. Es que la necesidad de crítica, reflexión y experimentación son cualidades cruciales para el diseño, y que se deben caltivar y resguardar. Ser mantenedor de realidades pre-impuestas es una atentado contra la evolución social y la innovación cultural -más allá de que la palabra innovación se haya convertido en un "caballito de batalla" de los mantenedores. La experimentación a la que están llamados los diseñadores es una ejercicio crucial para el desarrollo cultural e implica cuestionar los sistemas productivos, los procesos tecnológico, el aparato económico, el accionar de los medios, y en general todo el contexto en el cual el trabajo de diseño se realice. Esto incluso, eventualmente, podría llevar a establecer realidades similares a las defendidas por los mantenedores - no lo sabemos - pero este proceso debe nacer necesariamente desde la revisión, la crírica y el ensayo, ya çue es la única manera de explorar futuros posibles y con ello, potenciales mejoras en nuestras estructuras sociales. To back. To tinker:

Cuando he señalado que el actuar experimental al cual están llamados los diseñadores implica realizar un cuestionamiento general de los contextos en los cuales el diseño se lleva a cabo, el foco lo quiero hacer en los procesos tecnológicos. $Y$ es que en la sociedad occidental contemporánea, es la tecnología la que determina los procesos productivos, es la tecnología convertida en valor de cambio la que sustenta el aparato económico, y es la tecnología en cuanto infraestructura la que de base para al actuar de los medios. Por esta razón, propongo, el actuar crítico y reflexivo de los diseñadores debe centrarse en la tecnología y sus procesos. En cierto modo la historia siempre nos ha planteado esta problemática. La tecnología ha ido de la mano y la vez determinado el desarrollo de los distintos grupos culturales, y donde individuos específicos tuvieron el privilegio y responsabilidad de intervenir la técnica para hacerla evolucionar y avanzar hacia futuros posibles. Primero sabios dentro de la jerarquía gobernante, luego científicos e ingenieros y posteriormente ampliado a inventores, artistas y diseñadores, la apropiación de la tecnología de la época para su revisión, crítica y reconsideración ha sido siempre una necesidad pura de la evolución social e individual. El mismo diseño como disciplina nace a partir de esta disyuntiva. Cuando desde diversos sectores del arte surgieron reflexiones críticas respecto al rol que la tecnología y técnica tomaban en el día a día de las personas, aparece la necesidad de elaborar una nueva prácrica. Un referente fundamental en este fenómeno será siempre el Constructi- 
vismo Ruso, el cual ya en la tercera década del siglo xx propuso retóricamente un abandono del arte para avanzar hacia la construcción:

We didn't create technology.

We didn't create the man.

BUT WE,

Artist yesterday,

CONSTRUCTORS today,

Y. WE PROCESSED

the human being

2. WE ORGANIZED

technology

1. we discovered

2. PROPAGATE

3. CLEAN OUT

4. NERGE

PREVIOUSLX - Engineers relaxed with art

Now - Artists relax with technology... ${ }^{8}$

Para Aleksandr Ródchenko y sus pares constructivistas, el contexto histórico vivido - como hijos de la Revolución Industrial y testigos de la Revolución Rusa- determinó su actuar en pos de redefinir lo que se entendía por arte y la relación de éste con la tecnología. De aquel modo, y durante los primeros años de la Unión Soviética, personajes vitales para entender los movimientos avant-garde y el surgimiento del diseño como disciplina, como el mismo Ródchenko y El Lissitzky, trabajaron con matices en la búsqueda y construcción de una utopia, de un futuro ideal basado en el sueño soviético, tal como lo relata Victor Margolin en su libro The Struggle for Utopia? Esta referencia resulta paradigmática para nosotros hoy y debería empujarnos con fuerza a realizar una reflexión profunda respecto del estado de la práctica del diseño actual. Entonces jes posible establecer paralelos entre las circunstancias vividas por artistas avant-garde como los constzuctivistas y el contexto experimentado por los diseñadores hoy? Claramente sí. Las coincidencias comienzan con la transición histórica y el paso de un siglo a otro con todo lo que eso conlleva; aquellos artistas pasando del siglo Xxx al xx y la generación actual del XX al XXx. Pero por sobre todo están los hitos que han marcado ambos momentos. Los diseñadores de hoy; al igual que aquellos que lleguen a serlo en los próximos quince años; son hijos de una revolución tecnológica gigantesca que ha permeado intensamente - con distintos niveles y alcances - los procesos sociales y culturales de prácticamente todas las naciones del planeta y la forma en que sus 


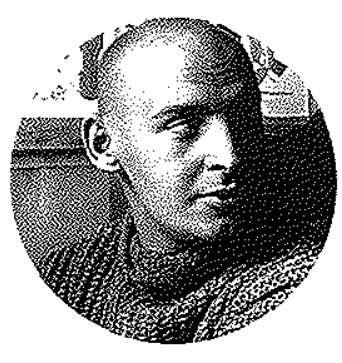

ciudadanos viven el día a día. Esta revolución tecnológica cuyas bases científico-teóricas más paradigmáticas podemos identificar en la década de 1930, pero que comienza a presentarse con evidencia más concreta durante los tres decenios posteriores, incorpora en nuestro actuar y pensar primero el computador y luego el ciberespacio, elementos que sin duda se constituyeron como determinantes en las últimas dos décadas del siglo $\mathrm{XX}$, en prácticamente todos los ámbitos del quehacer humano. Al mismo tiempo, el ambiente social y político ha ido evolucionando de manera tal que justamente hoy, ya en la segunda década del siglo XXI, surgen estallidos populares y revoluciones que comienzan a desarrollarse en cadena en diversos puntos del planeta, yendo desde la "primavera árabe" a los "indignados" españoles y desde el movimiento estudiantil chileno a la ocupación de Wall Street en Estados Unidos. Ahora bien, las coincidencias que podemos identificar entre el contexto vivido por los arristas avantgarde rusos y el que les toca experimentar a los diseñadores de hoy, son impresionantemente muchas. Entonces ¿ corresponde cuestionar hoy aquello en lo que el diseño se ha convertido? Absolutamente sí. Es urgente decidir si queremos validar el hacer del mantenedor o si preferimos movernos para retomar el camino del diseñador, es decir, el de aquel que trabaja haciendo desde la crírica y la reflexión, interviniendo la técnica para pensar y construir futuros posibles, tal como lo hicieran hace un siglo los constructivistas, tal como lo vienen haciendo desde hace algún tiempo los hackers.

\section{El diseñador-hacker}

Los diseñadores de hoy, y los que pronto vendrán, deben cuestionar su contexto, su propio hacer, cómo éste se desarrolla en la sociedad, y apropiarse de la técnica para pensar e iniciar la construcción de nuevos futuros posibles. Ver en el hacker un referente en lo concerniente a estos aspectos de actitud y acción, es un paso fundamental para comen$z a r$ a desarrollar esta tarea con la potencia y alcance necesarios. $Y$ es que debemos visualizar con eficiencia y rapidez las restricciones que impone hoy la infraestructura tecnológica y medial en nuestras sociedades. Es inconcebible vislumbrar cualquier intervención y desarrollo cultural sustancial sin tomar en cuenta e involucrarse en esta problemázica. Debemos entender que el contexto actual está supeditado, en prácricamente todos los ámbitos de la cultura, a la estructura de redes socio-técnicas y protocolos cuyo manej̧o y control implica hoy poder económico y políico. Astí, cuando escuchamos frases como "sociedad y economía de la información", estamos precisamente ante la referencia conceptual de este fenómeno. Entonces, ¿cuales son las capacidades 
que el diseñador debe alcanzar para intervenir la cultura de manera sustantiva en este contexto? Partamos diciendo pues, que una palabra más interesante para referirse al intervenir es precisamente hackear, y eso, ya nos dice bastante.

Si entendemos y concordamos en que nos encontramos dentro de un modelo de sociedad donde la infraestructura tecnológica y la información que circula a través de ella son elementos de cambio, y al mismo tiempo, mecanismos de administración del poder; y existe en nosotros la convicción de intervenir reflexivamente desde el hacer esa situación para participar en el desarrollo futuro de aquel contexto; entonces, veremos como necesidad fundamental el sumergirnos en los quehaceres de la técnica. En términos de filosofía hacker esto involucra trabajar con código, es decir, conocer lenguajes de programación y poder crear a través de ellos. En consideración de lo anterior, el trabajo con código - la programación- no pucde entenderse sólo como producción de infraestructura y seguimiento de protocolos predefinidos. Como nos lo recuerda Galloway, al igual que los lenguajes naturales, el código constituye un sistema complejo con sintaxis y gramática propia, que permiten analizar, descomponer, reconstruir y crear nuevas situaciones, con un potencial semántico que puede ir desde lo real a la ficción y desde el arte a lo científico ${ }^{\text {is }}$. En resumen, y quizá lo mas importante, tener la capacidad de crear con código implica tener el potencial para realizar las preguntas adecuadas y necesarias dadas las problemáticas que determinan el contexto en el que nos encontramos. Semejante iniciativa requiere de altas dosis de experimentación previa en pos de desarrollar la creación crítica y reflexiva que permita explorar los ideales socio-técnicos que sustentarán los procesos de intervención más adecuados de llevar a cabo. Así, esta dialéctica entre el conocimiento de la técnica compleja y la experimentación gallarda en y desde la cultura, define el carácter de este nuevo personaje: el diseñador-backer.

Sin duda lo anterior plantea una disyuntiva en lo referente a la formación de este nuevo actor. Por lo pronto y sobre todo para aquellos diseñadores que están ya ejcrciendo sus labores, seguir estos planteamientos implicará amplios esfuerzos de auto-aprendizaje y de desarrollo de iniciativas colectivas y colaborativas en este sentido. Pero el desafío que esto plantea a las instituciones académicas que formarán a las próximas generaciones de diseñadores es también sustancial e intenso. Las escuelas de discño han sido históricamente un engendro extraño, y es precisamente en la experimentalidad donde han encontrado y producido la incubación de creatividad

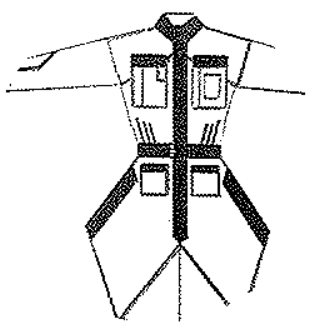
más profunda. Así, estos centros deben avanzar en gencrar los am- 


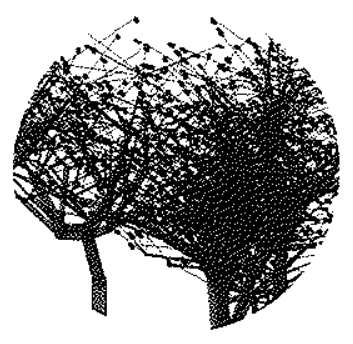

bientes y sistemas que sirvan de plataforma para el desarrollo de los nuevos y potenciales diseñadores-backer. No hacerlo, significará simplemente no saber leer las señales que la misma evolución histórica viene mostrando y que las diversas disciplinas del saber están Llamadas a recoger con urgencia, sobre todo en las denominadas insticuciones académicas complejas. Para el caso particular que aquí nos convoca, existen referencias de alto prestigio en este sentido, que sin duda vienen a confirmar el hecho de que estamos ante un fenómeno que no puede sino abordarse con seriedad y premura. Quiero mencionar así el caso del programa Design Interactions del Royal College of Art de Gran Bretaña, el cual, liderado por Anthony Dunne y Fiona Raby, se constituye como un ejemplo paradigmático para este artículo, y que viene desarrollando en buena medida muchos de los aspectos y problemáticas que acá he ido elaborando ${ }^{11}$. Dunne y Raby han centrado sus esfuerzos en la consecución de un ejercicio crítico del diseño desde un contexto tecnologizado, el cual a través del trabajo especulativo sienta bases para el desarrollo concreto de la disciplina en los posibles escenarios que diversos futuros podrian traer: ${ }^{2}$. A pesar de que en la perspectiva del programa Design Interactions la acticud backer es ejercida de manera más conceptual, el camino que propongo a través de este artículo es más pragmático. La valoración del empoderamiento tecnológico real resulta vital para nosotros en el Chile actual, inmersos en un ambiente regional donde justamente aquello ha sido históricamente dejado de lado, impidiendo una participación equiparada - y reflexiva - en los procesos que nos llevaron al contexto en el cual nos encontramos hoy. Así, en momentos donde curiosamente esfuerzos foráneos, que trabajan en la misma o similares líneas, nos permiten contar con las plataformas para sumarnos a los esfuerzos y corregir el rumbo, el camino de acción se debe tomar con decisión. Dicho eso, el diseñador-backer debe surgir como un individuo formado en gran balance entre las capacidades de análisis crítico y las habilidades de desarrollo y razonamiento socio-técnico que le permitan así, ser sagaz, punzante y llevar sus reflexiones a acciones concretas de intervención y participación cultural. La instituciones académicas complejas; ya sea en Chile o el resto de Latinoamérica; donde se cultive el diseño como práctica y disciplina, no pueden sino abordar este llamado, pues el momento histórico así lo demanda. Todo lo demás significará probablemente perpetuar lo extemporáneo y sus respectivas dosis de espectáculo. 


\section{Notas}

1. Galloway, Alexander; "Possibilily" [en lineal. Disponible en: http:/subsol.c3.hu/subsa:_2/contributors0/gallowaytext.htm

2. Oxford Student's Dictionary. Oxiord. Oxford University Press, 2007, p. 328

3. Hbid., p. 217

4. Banzi, Massimo: Getting Started with Arduino, Sebastopol, OReilly Media / Make, 2008, p. 5

5. Oxford Student's Dictionary; op. cit., p. 726

6. Glenny, Misha: "Hire the Hackess" [en linea]. Disponibie en: httg://www.ed.com/talks/lang/en/misha_glenny nire_the_hackers.htm!

7. Galleway, Alexander; Protocol: how controt exists alter decentralization, Cambridge, MIT Press, 2004, p. 167

8. Ródchenko, Aleksandr; Varvara Stepanova, Aleksei Gan; Graphic Design Theory: readings from the field, ed. Helen Armstrong. New York, Princelon University Press, 2009, p. 22

9. Margolin, Victor; The Siruggle for Utopia: Rodchenko, Lissitzky, Moholy-Nagy, 1917-1946, Chicago, The Chicago University Press, 1997, p. 10

10. Galloway. Alexander; op. cill, p. 164-167

11. Desion Interactions; Programme [en linea]. Disponible en: http://www.design-interactions.tca.ac uk/programme

12. Dunne, Antiony: Fiona Raby: "Critical Design FAQr [en linea]. Disponibie en: hitp:/www dunneandraby.co.uk/content/bydandr/13/0

13. http://wrw.sagmeister.com/laxonomy/term/32f/node/216 